\title{
El papel de la molienda en la transición hacia la producción agropastoril: Un análisis desde la Puna Meridional argentina
}

María del Pilar Babot ${ }^{1}$

\begin{abstract}
RESUMEN
Se efectúa una caracterización de la molienda en Antofagasta de la Sierra, Puna Meridional argentina, desde sus primeras manifestaciones hacia ca. 6500 años AP hasta el momento agropastoril más tardío. Para el análisis del cambio tecnológico se emplean los conceptos de eficiencia e intensidad de uso de los artefactos. Como resultado se establecen tres momentos en la organización de la práctica de la molienda, que marcan situaciones de intensificación creciente de la misma entre ca. 6500-1100 años AP.
\end{abstract}

Palabras claves: Noroeste Argentino - transición cazadores recolectores a sociedades agropastoriles - artefactos de molienda - intensificación - eficiencia de molienda - intensidad de molienda.

\section{ABSTRACT}

A characterization of grinding technology from ca. 6500 AP to late agro-pastoralist times at Antofagasta de la Sierra in Southern Argentinean puna, is made. Grinding efficiency and intensity concepts are used to analyze modifications on technology. As a result, three moments of change in the organization of grinding practice are established. They may be related to increasing intensification between ca. 6500-1100 AP.

Key words: Northwestern Argentina - transition from hunter-gatherers to agro-pastoralist societies - grinding stone tools - intensification - grinding efficiency - grinding intensity.

Recibido: julio 2005. Aceptado: marzo 2006.

\section{Introducción}

Se ha señalado que la intensificación de distintos aspectos como la producción, el uso de la tierra o de ciertos recursos, la desigualdad social, la jerarquización y diferenciación de los espacios,

1 CONICET - Instituto de Arqueología y Museo, Facultad de Ciencias Naturales e Instituto Miguel Lillo, Universidad Nacional de Tucumán. Juramento 759, (4000) San Miguel de Tucumán, ARGENTINA. Email: shypb@arnet.com.ar entre otros, constituyen indicadores centrales de los procesos de complejización que devinieron en las denominadas situaciones formativas tempranas y plenas del Noroeste Argentino (Scattolin 1990; Pérez Gollán 1991; Albeck 1993 Ms). En este marco, es de interés establecer en qué medida la etapa de transición hacia la producción coincide también con un momento de intensificación de las prácticas de molienda, más allá de la notable ubicuidad que las mismas adquieren al avanzar en el proceso.

Un conjunto de indicadores vinculados con el diseño artefactual y la organización de las prácticas se emplean para evaluar dicha hipótesis en el ámbito particular de Antofagasta de la Sierra, en la Puna Meridional argentina. Tales indicadores remiten a decisiones tecnológicas dirigidas a aumentar la eficiencia de molienda y posibilitar una mayor intensidad de uso de las piedras de moler, a los fines de un mejor aprovechamiento de tiempo, trabajo y rendimiento nutritivo de los recursos disponibles (Nelson y Lippmeier 1993; Wright 1994; Adams 1996; Hard et al. 1996). Como parte de este análisis, las características de los contextos de producción y uso de los artefactos se ponen en relación con elementos de la organización de los grupos prehispánicos y con factores del entorno ambiental, tales como pautas de movilidad/asentamiento y situaciones de riesgo de subsistencia y de trabajo/mano de obra (Escola 1996).

Observar los procesos de intensificación/desintensificación de la molienda desde la óptica de lo ocurrido en Antofagasta de la Sierra, ofrece la posibilidad de estudiar las primeras manifestaciones de dichos procesos y sus características cambiantes en una larga secuencia ocupacional que comienza en los $c a$. 9790 años AP y alcanza de manera prácticamente ininterrumpida, el momento colonial-moderno. En este marco de larga duración, las modificaciones ocurridas durante la transición hacia la producción son mejor comprendidas en su comparación con los elementos que caracterizan a los momentos previos y posteriores. 
La muestra de artefactos de molienda que se analiza en este trabajo está conformada por 39 instrumentos móviles enteros y fragmentados y ocho bloques fijos con una o múltiples superficies de molienda (22 en total). Estos proceden de contextos estratificados y depósitos de superficie de 11 sitios en el área (Figura 1) que se sitúan en: a) quebradas y pampas de altura (3800-4600 m.snm): Quebrada Seca 1 (QS1), Quebrada Seca 3 (QS3), y b) sectores intermedios (3550-3800 m.snm): Cueva Salamanca 1 (CSa1), Peñas Chicas 1.1 (PCh1.1), Peñas Chicas 1.3-sector A (PCh1.3-A), Punta de la Peña 4 (PP4), Punta de la Peña 4-pie de talud (PP4-pt), Punta de la Peña 9.I (PP9.I), Punta de la Peña 9.II (PP9.II), Punta de la Peña 9.III (PP9.III) y El Sembrado-alero (ES-a). En los mismos no se han recuperado otras clases de artefactos que no correspondan a instrumentos terminados o usados sin manufactura previa, y que puedan ser vinculados únicamente con el proceso de producción del instrumental de molienda, tales como artefactos para desgastar por fricción ${ }^{2}$, percutores e intermediarios. Una preforma de mortero móvil procedente de PP9.I constituye el único artefacto de la clase en proceso de manufactura (Babot 2004).

\section{La ocupación humana en el área de investigación}

Antofagasta de la Sierra, en la provincia de Catamarca, se enmarca en la fisiografía de la Puna Salada o Meridional argentina que constituye la continuación natural del altiplano peruano-boliviano. La secuencia ocupacional del área comienza en el Holoceno Temprano en los niveles inferiores de Quebrada Seca 3 (QS3) - ca. 9790 años AP. Se ha planteado para estos momentos un modelo de movilidad estacional programada entre zonas con alta disponibilidad de recursos, que incluye sitios funcionalmente diferenciados (Aschero 2000b).

Aparecen en estos primeros contextos elementos que caracterizarán a todos los cazadores recolectores de la Puna Meridional y que, en parte, perdurarán entre los grupos productores de la zona: explotación intensiva de camélidos como recurso multipropósito, utilización de reparos rocosos como sitios de residencia y/o actividades múltiples, y manejo de un amplio radio de acción para la obtención directa o por intercambio de distintos bienes (Hocsman et al. 2004).

2 Equivalente a “abrader" sensu Adams (1996).
Aproximadamente entre los 8000-4000 años AP ocurre una interrupción en los asentamientos humanos de la Puna Septentrional argentina y la puna chilena, los que pasan a estar representados sólo por ocupaciones muy esporádicas. Este registro coincide con el desmejoramiento climático del Holoceno Medio caracterizado por condiciones de mucho menor humedad a nivel macrorregional (Yacobaccio 1997; Núñez et al. 1999). Por contraposición, la secuencia de Antofagasta de la Sierra muestra una situación de mayor estabilidad ocupacional observándose sólo pequeños hiatos que duran no más de 500 años (Pintar 1996; Hocsman et al. 2004). Coincidentemente, la información paleoambiental señala su condición de "oasis" entre los 6700-3000 años AP (Olivera et al. 2002 Ms).

Este momento muestra un repliegue de las ocupaciones a sitios con disponibilidad permanente de agua y pasturas, como QS3 o Cueva Salamanca 1 (SCa1), los que habrían actuado como concentradores de recursos (Pintar 1996; Aschero 2000b). Al mismo tiempo se ponen en marcha distintas estrategias destinadas a su maximización, tales como modificaciones en las técnicas de caza (Aschero y Martínez 2001), e incrementos en el uso de especies vegetales foráneas (Rodríguez 1998, 1999).

Entre los 5500-5000 y 3500-3000 años AP tiene lugar un proceso de intensificación y complejización, que constituye un momento de transición hacia formas productivas en el área, vinculado con el inicio de las prácticas pastoriles y la domesticación de la llama (Lama glama) (Aschero 2000b; Hocsman 2002; Olivera et al. $2002 \mathrm{Ms}$ ). Por entonces, los sitios Punta de la Peña 4 (PP4), Peñas Chicas 1.1 (PCh1.1), Peñas Chicas 1.3-sector A (PCh1.3-A) y niveles superiores de QS3, muestran una alta densidad de vestigios (Aschero 2000b). Asimismo, se ha planteado una reducción en la movilidad residencial -incluyendo un uso reiterado del espacio-, con una obtención de recursos básicos para la subsistencia en un radio menor. Esta situación se asociaría a incrementos en la territorialidad, en el intercambio a larga distancia y en la densidad poblacional (Hocsman 2002).

El proceso de transición desde el modo de vida cazador recolector hacia otro de tipo agropastoril habría sido lento y variable. Este último tendría sus primeras manifestaciones en diversos sectores del Noroeste Argentino en torno a los 3000-2500 años AP hasta los 1400-1200 años AP (Olivera y Palma 1997; Olivera 2001). 


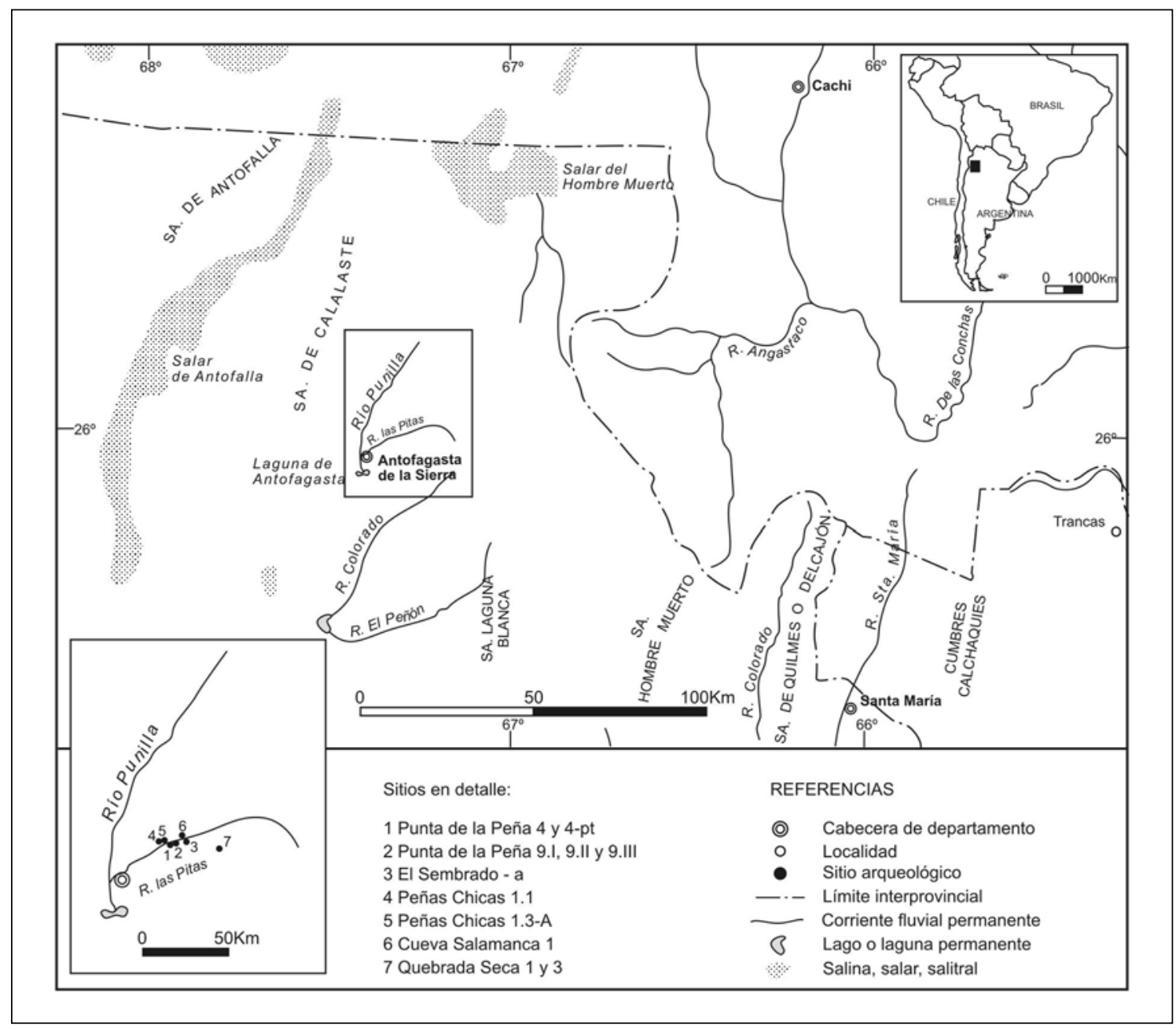

Figura 1. Area de Antofagasta de la Sierra (Catamarca, Noroeste Argentino), con la ubicación de los sitios arqueológicos analizados en este trabajo.

En el ámbito puneño se habría dado un paulatino incremento del sedentarismo, un rasgo que caracteriza a todo el Holoceno en Antofagasta de la Sierra (Pintar 1996). No obstante, los sistemas de asentamiento conservarían aún un importante dinamismo, conectando sitios de ocupación permanente con otros de residencia transitoria y de funcionalidad específica en zonas de producción, caza y/o recolección (Olivera y Palma 1997; García 1998; Aschero 2000b; Olivera 2001; Olivera et al. 2002 Ms; Olivera y Vigliani 2000-02; López Campeny et al. 2005).

El momento pastoril-agrícola más temprano está representado en Antofagasta de la Sierra por los niveles inferiores del sitio Casa Chávez Montículos fechado entre los ca. 2400-2100 años AP (Olivera 1992). Con posterioridad a ca. 2000 años AP habría habido una mayor incidencia de la producción agrícola asociada a cambios en el manejo del espacio (Olivera y Vigliani 2000-02), así como asentamientos más numerosos que incluyen ocupaciones en: Casa Chávez Montículos, Río Miriguaca, Confluenciasector A, Peñas Coloradas-BARLP, Punta de la Peña 9.I, Punta de la Peña 9.II (PP9.II), y algunos episodios en PP4 (Podestá 1986-87; Aschero 1999; Escola 2000 Ms; López Campeny 2001 Ms; Olivera 2001; Olivera et al. 2002 Ms; Olivera y Vigliani 2000-02; Babot 2004; López Campeny et al. 2005; Babot et al. $2006 \mathrm{Ms}$ ).

La historia siguiente al 500 DC está marcada en distintos puntos por cambios en la organización social y las relaciones de poder (Aschero 1999). Tiene lugar el establecimiento de verdaderas aldeas 
-bases residenciales de actividades múltiples-(López Campeny et al. 2005), sin embargo, la estructura básica de recursos y el manejo de microambientes no habrían sufrido grandes modificaciones (Olivera 1992; García et al. 2000). A partir de esta fecha y en los cinco siglos posteriores se sitúan las siguientes ocupaciones analizadas en este trabajo: PP9.III, El Sembrado-alero (ES-a) y Punta de la Peña 4pie de talud (PP4-pt) (López Campeny $2001 \mathrm{Ms}$; Babot 2004; Cohen 2005 Ms; López Campeny et al. 2005). Desde los ca. 700 años AP ocurren los asentamientos asignados al tardío, caracterizado por modificaciones sociopolíticas en los grupos (Olivera y Vigliani 2000-02). A este momento corresponden grandes conglomerados habitacionales como La Alumbrera y extensas áreas de producción agrícola, como Bajo del Coypar ligados al aumento de la importancia de la agricultura en la economía (Olivera y Vigliani 2000-02).

\section{Tecnología e intensificación}

Conceptos sobre intensificación.

Intensificación de las prácticas de molienda

Independientemente del enfoque que se adopte en el análisis de los procesos de intensificación, este es un concepto central para entender el cambio en los sistemas productivos. Por producción se entiende, en una concepción amplia, a todas “(...) las acciones de manufactura, construcción o creación llevadas a cabo por parte de los seres humanos" (Morrison 1994: 114).

La noción de intensificación hace referencia a un elemento constante y a otro variable. En particular, la intensificación en la producción “(...) se refiere a un incremento en el rendimiento productivo por unidad de tierra o de mano de obra (labor) o de alguna otra cantidad fija" (Morrison 1994: 115). Este incremento puede llevarse a cabo de diferentes maneras, y la variable constante puede ser la tierra en referencia al alimento producido, la oferta de recursos de un espacio dado en la actividad de caza-recolección, o bien el trabajo cuando se estudia la producción/uso de tecnofacturas. También se ha hecho referencia a la intensificación tecnológica, cuando es esta última la que se modifica -mediante la utilización de artefactos y técnicas más eficientes- para aumentar el rendimiento obtenido por unidad de tierra o de mano de obra (Morrison 1994, 1995).

En la concepción de Morrison (1994), la noción de intensificación posee una dimensión temporal implícita a lo largo de la cual deben establecerse las tendencias del proceso. En un análisis de mediano plazo, el mismo puede presentarse como algo no lineal e interrumpido por etapas de extensificación o desintensificación.

Según Kaiser y Voytek (1983, cit. en Morrison 1994), los procesos de intensificación pueden llevarse a cabo mediante la implementación de tres tipos de estrategias alternativas o complementarias: especialización, diversificación e intensificación propiamente dicha. Las tres implican cambios en la cantidad y organización de la mano de obra, y en su aplicación a través de la tecnología:

a) La intensificación propiamente dicha, es: el “(...) proceso por el cual se incrementan los rendimientos por unidad de tierra y/o mano de obra de una base de recursos existentes" (Morrison 1994: 142). Puede implicar incrementos en la frecuencia de obtención de recursos o de realización de actividades, la mejora en la eficiencia de las tareas o incrementos en la demanda de mano de obra o de tiempo de trabajo.

b) La especialización es la reducción de la diversidad, o canalización de la producción hacia fines restringidos (Morrison 1994, 1995). La especialización implica, por ejemplo, la manufactura de instrumentos especializados que promueven la eficiencia.

\section{c) La diversificación:}

“(...) puede implicar la adición o elaboración de estrategias productivas que pueden parecer más extensivas que intensivas en relación a la tierra o el trabajo. La diversificación se relaciona tanto con un incremento en la cantidad de componentes de un sistema productivo (diversidad), así como con cambios en la organización de dicha diversidad" (Morrison 1994: 144).

La diversificación temporo-espacial de las actividades puede incluir estrategias tales como la utilización de localidades dispersas, distintas épocas de producción y recuperación de los productos, cambios en la organización del trabajo o la mano de obra, y la utilización de múltiples recursos, cada uno con características de procesamiento y consumo particulares.

d) La expansión puede tener el componente de intensificación cuando lo que se expande es una práctica intensificada (Morrison 1994, 1995). 
En síntesis, la intensificación de las prácticas productivas se refiere a: a) la inversión de tiempo y trabajo puesta en la construcción y mantenimiento de los elementos materiales, y la dedicada a la organización de la mano de obra; y b) al esfuerzo de preparación y realización de la tarea en sí, más su frecuencia. Estos comportamientos son accesibles en el registro arqueológico a través del análisis de indicadores tecnológicos y de uso, y de la distribución espacial de las actividades. La Tabla 1 resume las particularidades en el caso de intensificación de las prácticas de molienda.
Intensificación de la molienda y desarrollos tecnológicos.

Eficiencia e intensidad de molienda

La intensificación de las prácticas de molienda tiene sus correlatos al nivel de los diseños artefactuales, sus modos de utilización y la organización del trabajo en torno a dicha actividad -esto último reflejado en los loci de molienda. En este marco, los cambios en los conjuntos de molienda son vistos como el resultado de desarrollos tecnológicos que responden a problemas creados por nuevos requerimientos

\begin{tabular}{|c|c|}
\hline 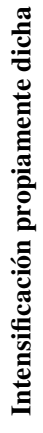 & $\begin{array}{l}\text { - Desarrollos tecnológicos destinados a mejorar la eficiencia de molienda de los instrumentos: } \\
\text { a) Cambios en los diseños artefactuales } \rightarrow \text { variables de diseño. } \\
\text { - Desarrollos tecnológicos destinados a incrementar la intensidad de molienda: } \\
\text { a) Cambios en los diseños artefactuales } \rightarrow \text { variables de diseño. } \\
\text { b) Indicadores de intensidad de uso } \rightarrow \text { análisis del desgaste y el descarte. } \\
\text { c) Cambios en la organización de la mano de obra } \rightarrow \text { molienda individual/en grupos } \rightarrow \text { loci de molienda. } \\
\text { d) Cambios en la disposición espacial de las actividades } \rightarrow \text { áreas fijas de molienda } \rightarrow \text { loci de molienda. } \\
\text { - Complejidad de las preparaciones o procesamientos previos a la molienda (lavado, tostado, aventamiento, etc.) } \\
\rightarrow \text { análisis tafonómicos de microrrestos vegetales y residuos de uso. } \\
\text { - Dependencia de la molienda durante el año } \rightarrow \text { indicadores de estacionalidad } \rightarrow \text { análisis de sustancias adheridas. }\end{array}$ \\
\hline 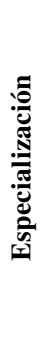 & $\begin{array}{l}\text { - Requerimientos materiales, espaciales y organizacionales estrictos y específicos, que posibilitan una mejora en la efi- } \\
\text { ciencia de molienda y una mayor intensidad de molienda } \rightarrow \text { variables de diseño y análisis de los loci de molienda. } \\
\text { - Dependencia del grupo respecto de dichas prácticas, evidenciada en un incremento en la intensidad de molienda } \rightarrow \\
\text { variables de diseño, análisis del desgaste y el descarte, loci de molienda. } \\
\text { - Manufactura de instrumentos con diseños especializados para las funciones básicas y específicas } \rightarrow \text { variables de } \\
\text { diseño y análisis de la estandarización. } \\
\text { - Enfasis en el procesamiento de ciertos recursos específicos disponibles } \rightarrow \text { análisis de sustancias adheridas. }\end{array}$ \\
\hline 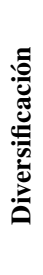 & $\begin{array}{l}\text { - Variedad dentro de las prácticas, con sus requerimientos materiales, espaciales y organizacionales específicos } \\
\rightarrow \text { variables de diseño y loci de molienda, análisis de sustancias adheridas. } \\
\text { - Diversidad de las preparaciones y procesamientos previos a la molienda } \rightarrow \text { análisis tafonómicos de microrrestos } \\
\text { vegetales y residuos de uso. } \\
\text { - Distintas temporadas de molienda vinculadas con el procesamiento de diferentes recursos con disponibilidades anuales } \\
\text { variadas } \rightarrow \text { indicadores de estacionalidad } \rightarrow \text { análisis de sustancias adheridas. }\end{array}$ \\
\hline 产 & $\begin{array}{l}\text { - Ubicuidad de los instrumentos de molienda } \rightarrow \text { porcentaje de sitios sincrónicos con registro positivo. } \\
\text { - Incremento en la cantidad de instrumentos de molienda dentro de cada sitio } \rightarrow \text { número de artefactos. }\end{array}$ \\
\hline
\end{tabular}

Tabla 1. Manifestaciones de la intensificación en las prácticas de molienda e indicadores arqueológicos. 
sociales. Ahora bien, los desarrollos tecnológicos generados para satisfacer las necesidades de una práctica de molienda intensificada pueden, en términos generales, privilegiar alguno de los siguientes aspectos: a) favorecer el uso más eficiente de los artefactos o mejorar la eficiencia de molienda, y b) posibilitar el incremento del tiempo continuo invertido en la tarea de molienda o la intensidad de molienda (Adams 1993, 1996, 1999).

La eficiencia de molienda "(...) es la cantidad de esfuerzo invertido en la tarea de molienda" (Adams 1993: 333), pudiendo ser medida por la cantidad de producto procesado por unidad de tiempo (Adams 1993, 1996).

Diversos investigadores han calificado a diferentes diseños de instrumentos de molienda como más o menos eficientes. Sin embargo, han sugerido que la eficiencia de molienda se relaciona, principalmente, con el área de la superficie de molienda en los artefactos activos y pasivos, de tal manera que los más grandes son mejores en este sentido, permitiendo ahorrar tiempo de procesamiento (Horsfall 1987; Adams 1993, 1996, 1999; Diehl 1996; Hard et al. 1996).

No obstante, se ha sostenido que, aunque los artefactos con áreas de molienda más grandes procesan más rápidamente y, por lo tanto, utilizan menos tiempo, requieren, a la vez, de un esfuerzo considerable durante su utilización (Adams 1993; Hard et al. 1996). Habría, entonces, un límite para el tamaño de los instrumentos, dado por la fuerza y la resistencia humanas, que pone un tope a la eficiencia de los artefactos. Si esta última no fuera la suficiente como para dar respuesta a los requerimientos de productos molidos, entonces la inversión de una mayor cantidad de tiempo en la tarea de molienda constituiría una solución posible, y este sería el punto en el que la intensidad de molienda se convierte en un concepto central (Adams 1993, 1996).

La intensidad de molienda “(...) es la cantidad de tiempo continuo invertido en cada tarea de molienda" (Adams 1996: 35). Es una medida relativa que considera que, por ejemplo, una mano usada para una tarea durante cuatro horas ha sido usada más intensivamente que otra empleada en cuatro tareas de una hora cada una (Adams 1993, 1996). No requiere necesariamente de artefactos de mayor tamaño, aunque estos puedan resultar apropiados dada su eficiencia. En cambio, el diseño de los artefactos que se emplean en sesiones largas tiene en cuenta las limitaciones de la fuerza y resistencia humanas, así como la resistencia del material al desgaste; asimismo, involucra la puesta en práctica de técnicas para administrar el desgaste por uso con el fin de prolongar la vida útil de los instrumentos (Adams 1993).

Ambas estrategias se ven favorecidas por la utilización de artefactos cuyos diseños se caracterizan por la combinación de algunos de los elementos enunciados en la Tabla $2 .^{3}$

Según Adams (1993, 1996), los cambios en la eficiencia de molienda e intensidad de uso están destinados, principalmente, a resolver problemas de conflictos de tiempo con otras actividades, a abastecer a un número mayor de gente o a generar una mayor cantidad de producto molido de la siguiente manera:

a) Una mejora en la eficiencia implica menos tiempo invertido en la molienda para alimentar a la misma cantidad de gente con el mismo monto de producto molido. Esto implica que quienes desarrollan la práctica disponen de más tiempo libre para participar de otras actividades.

b) Una mejora en la eficiencia implica la misma cantidad de tiempo invertido en la molienda para alimentar a más gente o para incrementar el monto de producto molido en la dieta.

c) Un incremento en la intensidad implica más tiempo invertido en la tarea de molienda, ya sea para alimentar a una cantidad mayor de gente o para incrementar el monto de producto molido en la dieta.

\section{Cambio tecnológico e intensificación de la molienda en Antofagasta de la Sierra}

Sobre la base de la evidencia disponible para la totalidad de los sitios con registro de molienda ubicados en quebradas de altura y sectores intermedios dentro de Antofagasta de la Sierra, y para su lapso de ocupación completo, se postulan tres momentos para el análisis de las prácticas de molienda: a) $c a$. 6500-5400 años AP, b) ca. 5400-3200 años AP, y c) $c a .3200$ años AP hasta $c a .1100$ años AP.

\footnotetext{
3 Para mayores detalles acerca de los elementos de diseño que favorecen la eficiencia de molienda y la intensidad de uso, consultar Babot (2004).
} 


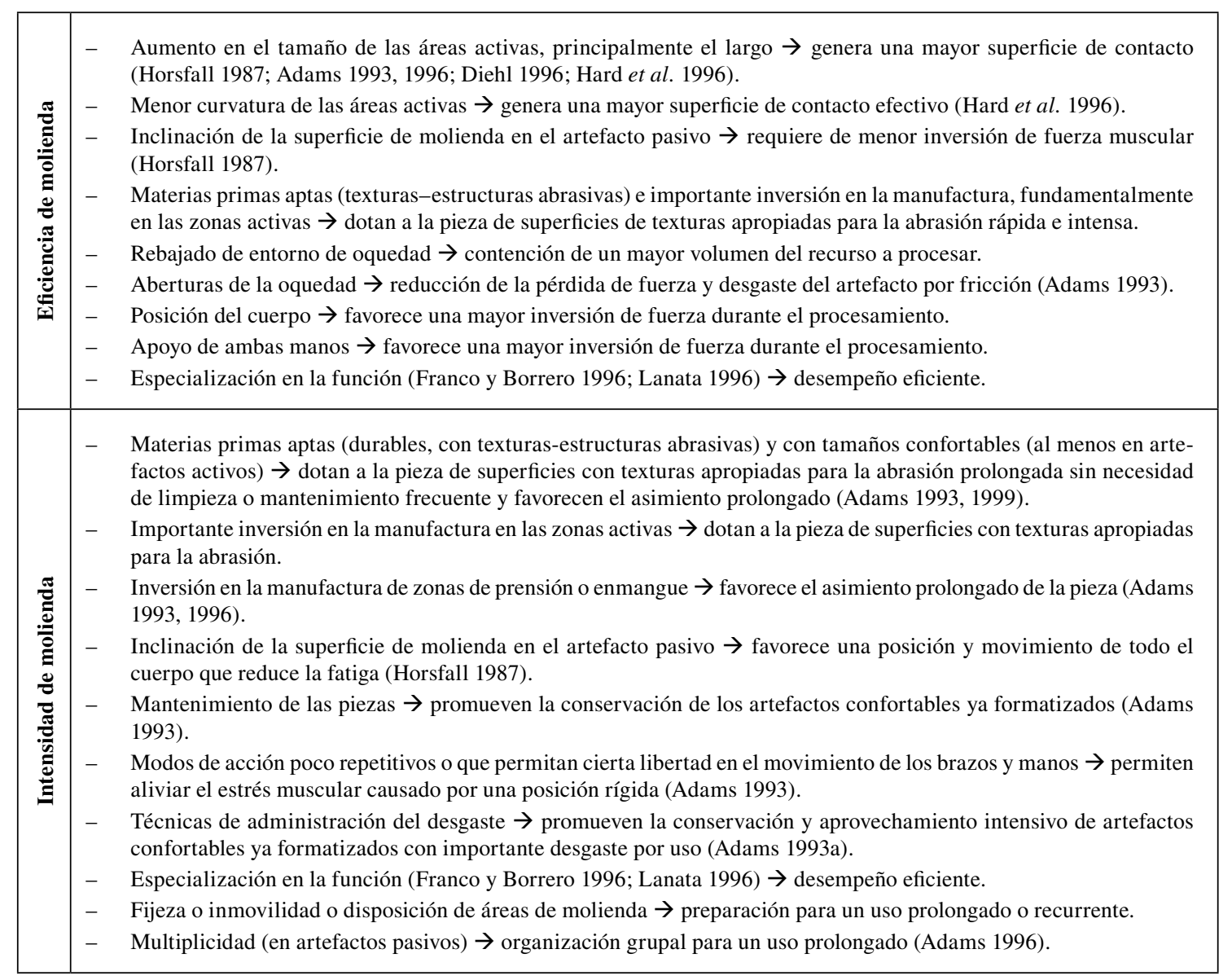

Tabla 2. Características del diseño de los artefactos destinadas a favorecer la eficiencia de molienda y la intensidad de uso.

Las figuras 2, 3, 4 y 5 resumen de manera comparativa las características de los artefactos e indicadores tecnológicos que se han considerado para abordar la cuestión de la intensificación y cambio en los tres momentos postulados. Dichas evidencias se discuten a continuación.

\section{Primer momento (ca.6500-5400 años AP)}

Este lapso contiene las primeras manifestaciones de la molienda en el sector de la Puna Meridional consideradas en este trabajo. Aunque las evidencias son reducidas en número, señalan la adopción de una nueva tecnología en el repertorio de los cazadores recolectores del Holoceno Medio. Es importante destacar que la misma hace su aparición en momentos más o menos tardíos, esto es, aproximadamente 3200 años después del comienzo de la ocupación humana en Antofagasta de la Sierra. Sin embargo, estos constituyen los datos más tempranos de instrumental de molienda conocidos en el Noroeste Argentino, los cuales son aproximadamente 2000 años más jóvenes que los registros más antiguos del sector norte de la Puna de Atacama argentina.

Las primeras manos de Antofagasta de la Sierra corresponden al nivel 3 del sitio Cueva Salamanca 1 con una cronología estimada entre $6250 \pm 70-7500 \pm 60$ AP a partir de los fechados de los niveles supra e infrayacentes (Pintar 2004 Ms-a, 2004 Ms-b) y a la capa 2b(9) de QS3 (ca. 6100 años AP; Aschero 1999). Estos son los únicos contextos con registro de molienda hasta el momento, en una proporción de un instrumento/ocupación, lo que pone en evidencia la escasa representación de dicha tecnología con anterioridad a ca. 5400 años AP. En ambos casos se trata de manos de molino, lo que indica ausencia de diversidad dentro de la clase artefactual considerada. 


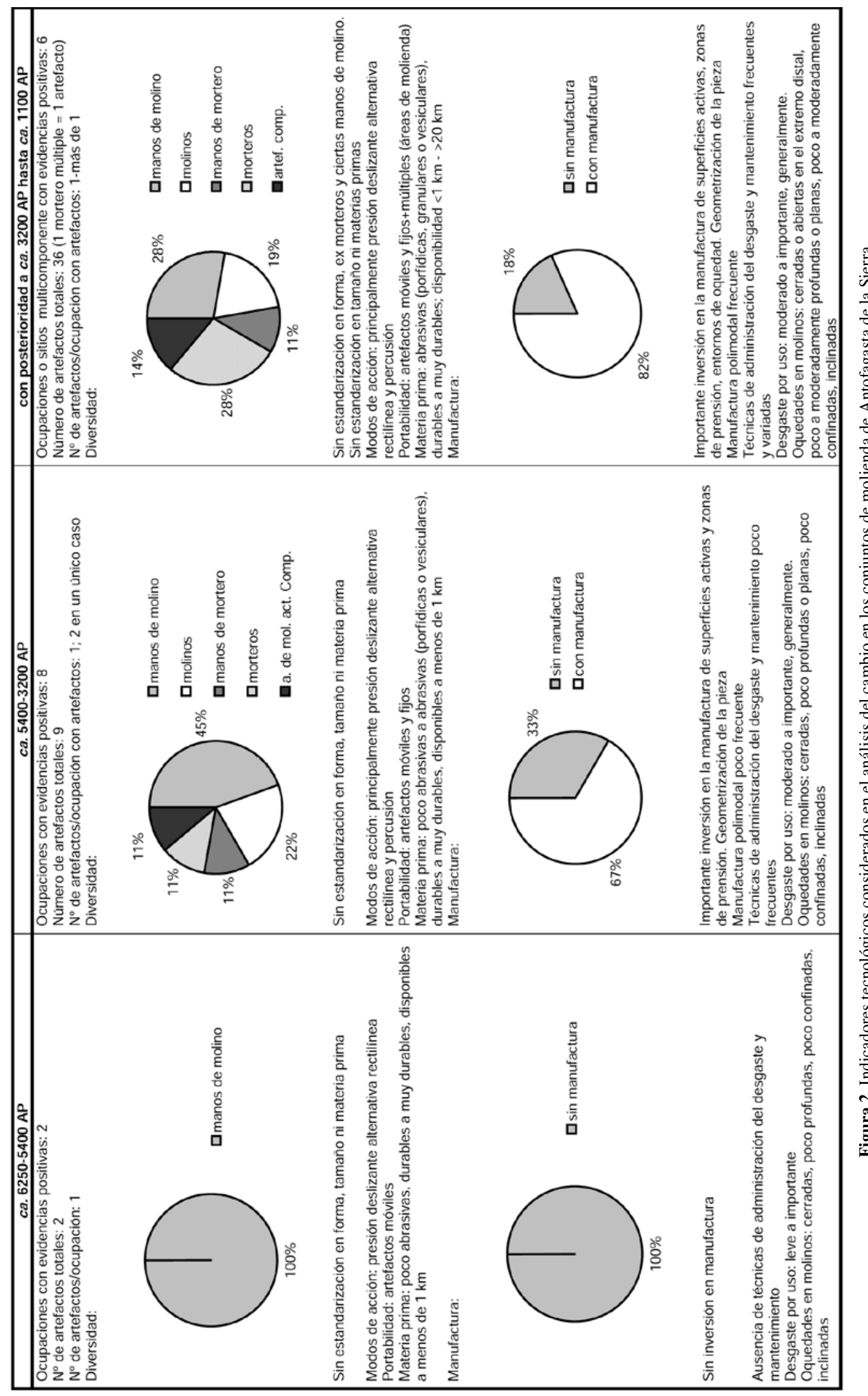




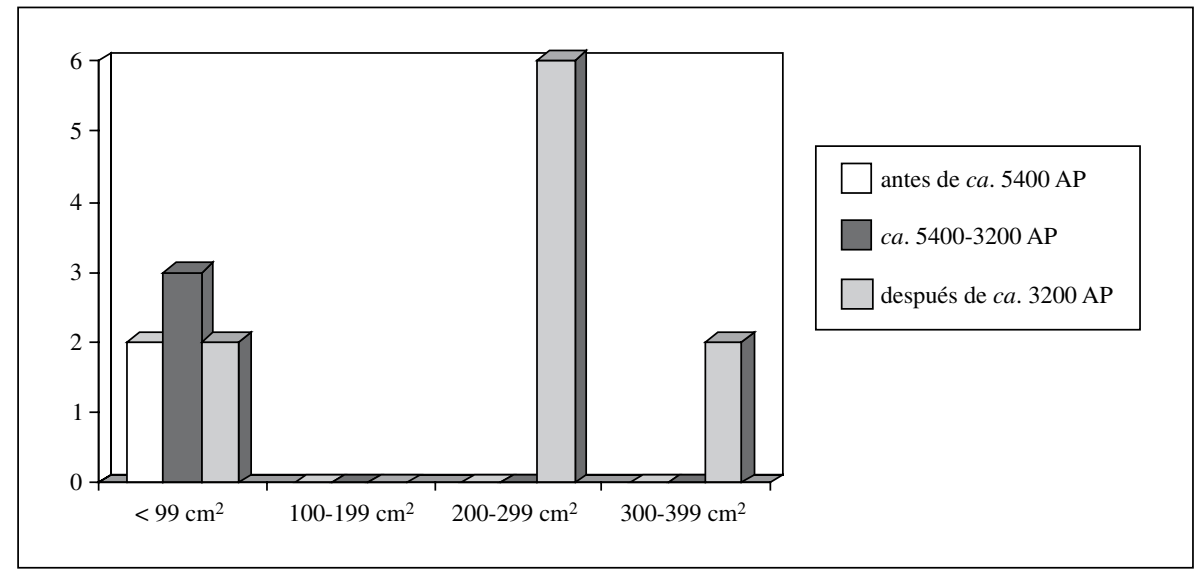

Figura 3. Area de molienda en manos de molino de Antofagasta de la Sierra. Se consideran las manos de molino enteras y fragmentos que representan más de la mitad de la pieza completa.

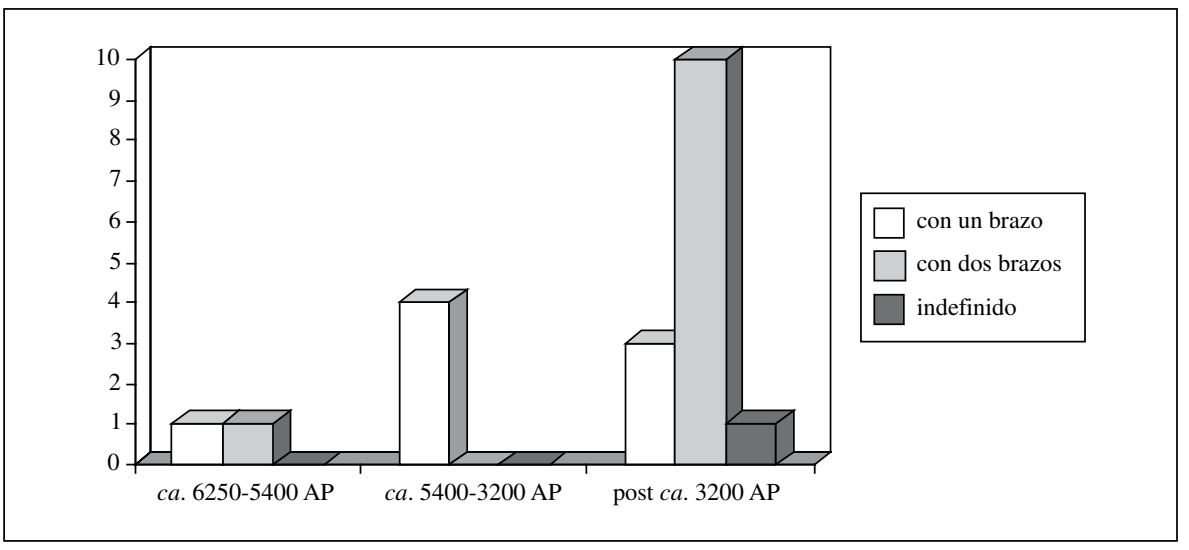

Figura 4. Manipulación de manos de molino en Antofagasta de la Sierra.

Caracteriza a estas piezas la ausencia de manufactura, mantenimiento y administración del desgaste. Las mismas presentan diferencias de forma, tamaño y materia prima, por lo que carecen de estandarización. No existen evidencias que indiquen que los instrumentos fueron concebidos para desarrollar eficientemente su tarea, destinados a perdurar en el tiempo, o mantenidos con la intención de su utilización periódica y reiterada, más allá de los límites impuestos por las propias materias primas y formas base. El área de las superficies activas es reducida; la misma no supera los $100 \mathrm{~cm}^{2}$ por lo que el monto de producto molido debió ser limitado.

Cuatro aspectos que se encuentran presentes en estos primeros artefactos permanecen a lo largo de toda la secuencia ocupacional, por lo que no pueden ser utilizados como indicadores de cambio tecnológico.
Aún en los casos en los que se trata de artefactos de rápido descarte, estos se vinculan con la búsqueda de eficiencia en el desempeño de la tarea, a través de los modos de acción implementados, y de atributos que se presentan naturalmente en las materias primas $\mathrm{y}$ formas base seleccionadas:

a) Modo de acción de tipo presión deslizante alternativa rectilínea. Este constituye una manera de lograr el mayor contacto efectivo posible entre las dos superficies de molienda durante toda la tarea. Sin embargo, se trata de acciones repetitivas efectuadas en una posición rígida, que pueden provocar fatiga muscular al ser implementadas por tiempo prolongado (Adams 1993).

b) Confort en la manipulación de los artefactos, dada por formas naturalmente anatómicas y tamaños 


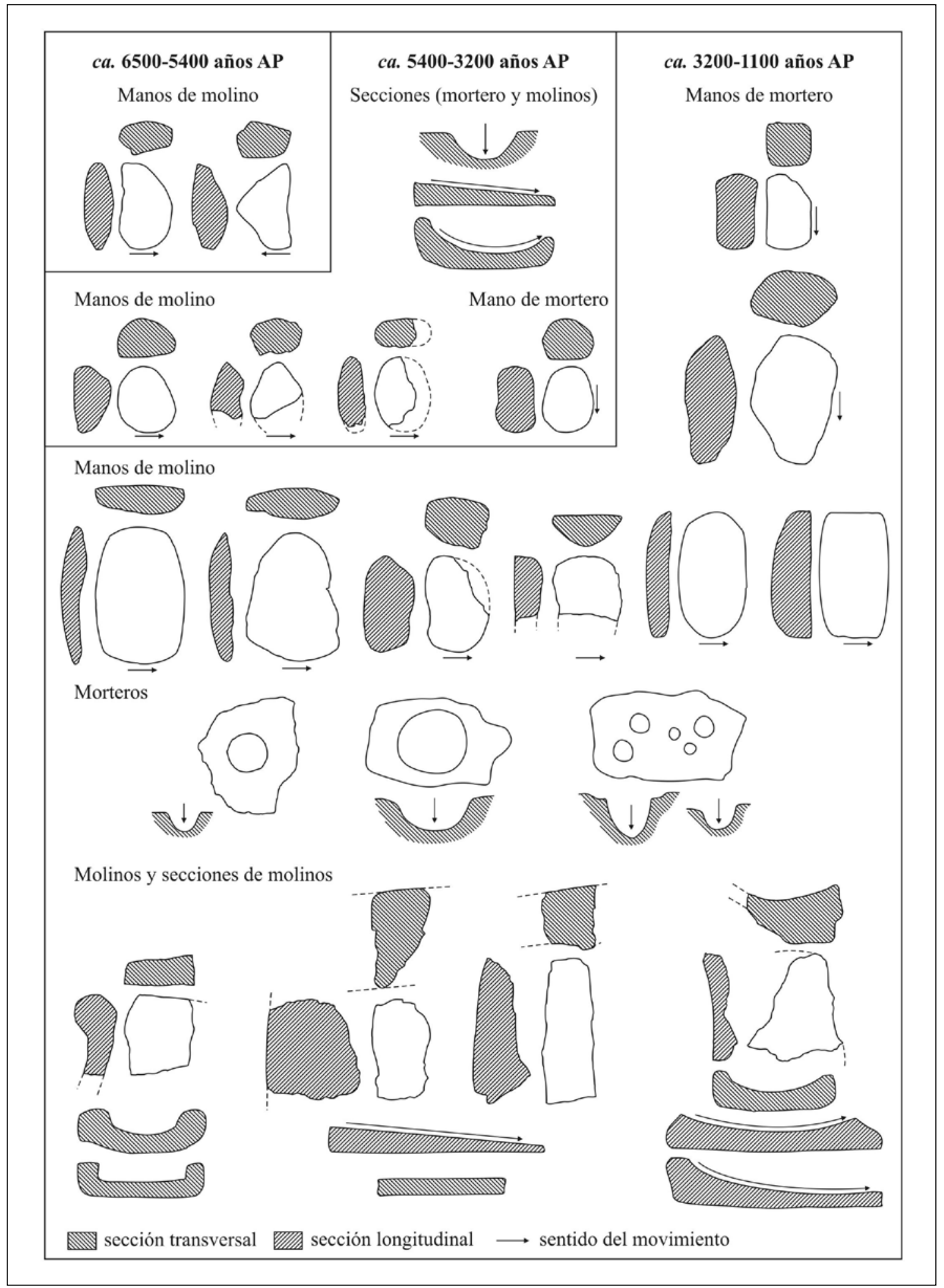

Figura 5. Siluetas y secciones de artefactos de molienda enteros y fragmentados y secciones de artefactos pasivos reconstruidas, correspondientes a los conjuntos de Antofagasta de la Sierra. 
adecuadamente manipulables. Esta circunstancia favorece el asimiento prolongado (Adams 1993, 1999).

c) Materias primas durables a muy durables. Dichas características facilitan un uso prolongado y evitan la introducción de componentes minerales de las rocas en el producto molido (Nelson y Lippmeier 1993).

d) Diseño de las oquedades de los molinos, cerradas en sus laterales y extremos, poco profundas e inclinadas. Las zonas activas con curvaturas leves propician una mayor superficie de contacto efectivo durante la tarea (Hard et al. 1996), en tanto que las oquedades poco confinadas evitan roces innecesarios de los artefactos complementarios durante la molienda. La inclinación de la superficie activa del artefacto pasivo favorece una posición del cuerpo descansada y una direccionalización de la fuerza muscular hacia la acción de la mano sobre las sustancias molidas (Horsfall 1987).

En el caso de la mano de QS3, el escaso desgaste por uso apunta a un empleo ocasional o imprevisto seguido de descarte. Su utilización como percutor sugiere que no hubo un cuidado especial en evitar el daño producido por otros usos distintos a la molienda. Esta situación es coincidente con la esperada para sitios de actividades específicas (Nelson y Lippmeier 1993) como es en este caso, una estación de caza (Aschero et al. 1991; Pintar 1996; Aschero 1999).

La situación de CSa1 difiere en los aspectos relativos a la utilización de la pieza. La mano de moler procedente de este sitio presenta un importante desgaste por uso, señalando que la tarea de molienda se desarrolló durante un tiempo prolongado, o bien, como consecuencia de usos reiterados, a juzgar por la dureza de la materia prima cuarcítica del instrumento. Además, la morfología y el tamaño de la pieza sugieren que debió manipularse con los dos brazos. Esta modalidad favorece el empleo de mayor fuerza durante el procesamiento. Aunque el desgaste se debería, en parte, a tareas no específicamente relacionadas con la molienda-el procesamiento de tejidos vegetales no comestibles (Babot 2004)- el rango de uso sugiere que el artefacto pudo pasar a integrar el equipamiento permanente del sitio, y ser reutilizado a partir de un empleo inicial más bien ocasional. Las características de utilización y el descarte como residuo de facto en este caso coinciden con lo esperado para sitios con ocupaciones regulares o prolongadas (Nelson y Lippmeier
1993), tal como habría sido CSa1 en su rol de base residencial (Pintar 1996).

Las manifestaciones iniciales de la molienda se encuadran en el comienzo de un período de menor humedad para el área considerada (Olivera et al. $2002 \mathrm{Ms}$ ), en el que las ocupaciones se hallan replegadas a sitios con disponibilidad permanente de agua y pasturas (Pintar 1996; Aschero 2000b). En este marco, los primeros artefactos de molienda de la secuencia ocupacional de Antofagasta de la Sierra implican el manejo de una nueva tecnología en una situación de expansión de la dieta (Lanata y Borrero 1994; Bamforth y Bleed 1997). Sin embargo, esta lo hace en muy baja proporción y en forma de aportes ocasionales. Se trataría de diseños encuadrados en una estrategia "oportunística" (Nelson 1991), e implementados en el marco de un ambiente poco previsible. El registro de CSa1 indicaría, no obstante, que pudo haber una recurrencia en la utilización del equipamiento de molienda como resultado de ocupaciones reiteradas.

Los recursos de moler registrados a partir de microfósiles en residuos están constituidos por: tubérculos/raíces no diferenciados -silvestres o domésticos-, hojas de Arecaceae (Palmae), raíces tuberosas de Ciperaceae y frutos/hojas de Fabaceae silvestres o domésticos. También se han documentado restos de gramíneas y posiblemente de frutos de Lagenaria siceraria, pero su estatus como recursos de moler es incierto (Babot 2005).

\section{Segundo momento (ca. 5400-3200 años AP)}

Los datos considerados para este lapso proceden de evidencias de superficie de Quebrada Seca 1 (QS1), niveles $2 \mathrm{~b}(3)-4770 \pm 80$ AP (Aschero et al. 1991) - y 2b(2) -4510 \pm 100 AP (Aschero et al. 1991)-, Quebrada Seca 3, extracción 4, Peñas Chicas 1.1 (PCh1.1) -3660 \pm 60 AP (Pintar 1996)-, niveles 4 y 7 -respectivamente, $3490 \pm 60$ AP y $3670 \pm 60$ AP (Aschero et al. 1991; Hocsman 2006)-, Peñas Chicas 1.3-sector A (PCh1.3-A), y Capas 5(5) y 5(4) de Punta de a Peña 4 (PP4) - ca. 4100-3200 años AP (Aschero 1999). Debe destacarse que el límite superior fijado para este segundo momento está dado por un intervalo de $c a$. 5400-4500 años AP que constituye la cronología estimada para el arte rupestre de Quebrada Seca 1 (Aschero 1999, 2000a, 2000b), la cual se atribuye también al mortero fijo 1.QS1 que se halla emplazado en el piso rocoso de la cueva. Los artefactos de molienda con dataciones 
radiocarbónicas más tempranas para este lapso son posteriores a esa fecha y se sitúan en los $c a .4770$ años AP, correspondiendo al nivel 2b(3) de QS3 (Aschero et al. 1991).

Es posible sostener que son las ocupaciones de cazadores recolectores datadas a partir de este momento en adelante, las que marcan un punto de inflexión en las características de la tecnología de molienda. A juzgar por la evidencia disponible para este momento, la práctica de la molienda parece haber ocurrido aún a escala reducida, pero diferenciándose de la situación anterior y, a la vez, evidenciando ciertas tendencias que luego serán comunes en los contextos productivos posteriores.

Los datos para este momento suman un total de ocho ocupaciones y conjuntos de evidencias de superficie, que contienen nueve artefactos de molienda, a razón de un artefacto/ocupación. Si bien la cantidad de piezas recuperadas por unidad de análisis mantiene los valores bajos registrados para el lapso anterior, se destaca el número importante de contextos con registro de molienda, los cuales constituyen una proporción significativa del total de las ocupaciones conocidas en la zona para entonces.

Al grupo tipológico de las manos de molino registrado anteriormente, se suman manos de mortero, molinos y morteros, además de artefactos de molienda activos o superiores compuestos. La diversidad en términos de grupos es notable, si se tiene en cuenta que se trata de un número pequeño de artefactos analizados. Son las manos de molino, seguidas de los molinos, los que se encuentran en mayor proporción.

La molienda se desarrolla ahora, mediante el empleo de dos modalidades de procesamiento: molienda/pulverización y machacado/trituración. Por otro lado, al modo de acción por presión deslizante alternativa rectilínea se suman otros gestos entre los que se destaca la percusión. Distintos grupos artefactuales, modos de acción y funciones primarias indican la diversificación de la práctica.

Este grupo de artefactos se caracteriza por la ausencia de estandarización en su forma, tamaño y materia prima, aunque debe mencionarse que se trata, en su mayoría, de rocas de buena calidad para la molienda, dada por la presencia de texturas naturalmente abrasivas, porfídicas y vesiculares. No obstante, más de las dos terceras partes de las mismas presentan una importante inversión en su manufactura destinada a dotarlas de mayor eficiencia, la cual se localiza tanto en superficies activas como en zonas de prensión. Un resultado evidente del proceso de formatización es la regularización de las formas o su geometrización. Sin embargo, el empleo de manufactura polimodal, esto es, más de una técnica involucrada en la producción de los artefactos, no es frecuente.

En las superficies activas, al poder abrasivo de las rocas seleccionadas se suma el efecto del picado, mientras que al confort natural de las formas base se agregan modificaciones destinadas a mejorar la prensión y facilitar el asimiento prolongado. El empleo de técnicas de mantenimiento y administración del desgaste dirigido a prolongar la vida útil de los artefactos está presente, pero se reduce a menos de la mitad de los casos. Esto se vincula con el grado de desgaste que presentan los artefactos, el cual es moderado a importante. Dichas características implican que las actividades de molienda se llevaron a cabo en sesiones prolongadas y/o reiteradas.

Estos datos indican que los artefactos fueron concebidos para desarrollar eficientemente su tarea, destinados a perdurar en el tiempo, y mantenidos con la intención de su utilización periódica y reiterada, aún en circunstancias de abundancia local de materias primas aptas a menos de $1 \mathrm{~km}$ de distancia (Babot 2004). El rango de uso y las características de la manufactura indican que los instrumentos integraban los equipamientos permanentes de los sitios, fueron conservados en previsión de un uso futuro y se reutilizaron recurrentemente. Todos estos elementos y las circunstancias del descarte de una parte importante de ellos como residuos de facto, coinciden con lo esperado para sitios con ocupaciones recurrentes y anticipadas (Nelson y Lippmeier 1993).

El tamaño de los instrumentos es reducido, de tal forma que su manipulación debió llevarse a cabo empleando la fuerza de un solo brazo. En consonancia con esto, el área de las superficies activas de molienda no supera los $100 \mathrm{~cm}^{2}$, con lo que el monto de producto molido habría sido limitado, al igual que en momentos anteriores.

De acuerdo con estos indicadores, la molienda se habría convertido en una práctica más frecuente, y habría estado asociada a ocupaciones de tipo base residencial y transitorias caracterizadas por reocupaciones periódicas (Pintar 1996; Aschero 1999; 
Aschero et al. 2001; Hocsman 2002; Hocsman et al. 2003). Su implementación no sería ocasional, sino más bien planificada o programada, aunque aún a una escala reducida. En relación con el momento anterior, sin embargo, los indicadores tecnológicos tomados en conjunto señalan un incremento relativo en la eficiencia de uso e intensidad de la molienda. Ambas estarían relacionadas, a nuestro juicio, con la necesidad de procesar un monto mayor de recursos en el menor tiempo posible, a fin de disponer de este último para el desarrollo de otras actividades (Adams 1993, 1996).

Los recursos de molienda se habrían consumido en mayor proporción y con mayor regularidad, lo que sugeriría que tuvieron un papel más importante en la dieta que el que les fuera asignado anteriormente. A juzgar por los indicadores de uso identificados, se trata de una gama amplia de taxones vegetales domésticos y silvestres (Babot 2004). Hacia ca. 4700 años AP se tienen ejemplares procedentes de semillas de Chenopodium sp. aff. C. quinoa y frutos de Opuntia sp.; los frutos de Cucurbita sp. son otros casos posibles, pero no confirmados. Ejemplares de granos de Zea mays y hojas y pecíolos de Acrocomia sp. se documentaron en un artefacto de $c a .4500$ años AP. Entre 4100-3200 años AP se suman al mencionado repertorio: semillas de Amaranthus sp. aff. A. caudatus/mantegazzianus; tubérculos de Canna edulis, Oxalis tuberosa, Solanum tuberosum y Ullucus tuberosus; vainas de Prosopis sp. y frutos de Juglans australis. No hay registros de tejidos de Arecaceae (Palmae) (Babot 2005).

Las características que adquiere la molienda en el lapso analizado se encuadran coherentemente en las circunstancias señaladas para la ocupación humana de Antofagasta de la Sierra: inicio posible de prácticas pastoriles, en un contexto de movilidad residencial reducida, uso reiterado del espacio e intercambio a grandes distancias.

Tercer momento (con posterioridad a ca. 3200 años AP hasta $c a .1100$ años AP)

Los datos considerados para este lapso incluyen: evidencias de superficie de Punta de la Peña 9.I (PP9. I) $-1430 \pm 60$ AP a $c a .1100$ años AP (Babot et al. 2006 Ms)-, Punta de la Peña 9.II (PP9.II) y Punta de la Peña 9.III (PP9.III); nivel 3 de la estructura 2 de PP9.III posterior a $1150 \pm 150$ AP (López Campeny $2001 \mathrm{Ms}$ ); evidencias de superficie de Punta de la Peña 4 (PP4), Punta de la Peña 4-pie de talud (PP4-pt) y El Sembrado-alero (ES-a). Diferentes indicadores señalan que todos ellos se sitúan con posterioridad al inicio de nuestra era, por lo que existe un hiato de más de mil años en cuanto a sitios residenciales (Hocsman 2002) que, por ahora, no es posible de subsanar.

Los conjuntos artefactuales correspondientes a los primeros siglos de la era muestran una marcada continuidad respecto de la situación registrada antes de los $c a .3200$ años AP. Sin embargo, las características de los diseños artefactuales y la organización de la molienda en las ocupaciones de grupos productores muestran que la misma se encuentra notoriamente intensificada. Los elementos que indican su especialización, diversificación, expansión e intensificación propiamente dicha (Morrison 1994), así lo sugieren. En efecto, el primer indicador en este sentido lo constituye la prácticamente total ubicuidad de los artefactos de molienda en sitios con contextos domésticos. Además de estar representados en la mayor parte de los conjuntos líticos de grupos agropastoriles, estos se encuentran en un número importante. Tomando en consideración únicamente los datos utilizados en esta investigación, se tienen nueve contextos con registro positivo de instrumental de molienda, a razón de uno o más artefactos/ocupación o conjunto de evidencias superficiales. Esta cifra se incrementa en más de un orden de magnitud si se consideran todas las superficies activas de molienda presentes en artefactos dobles, triples y múltiples.

Los conjuntos correspondientes a este lapso no muestran diferencias notorias respecto del número de grupos tipológicos registrados previamente. En efecto, se cuenta con piezas asignadas a los cuatro grupos de artefactos de molienda, más artefactos compuestos por superficies de molienda en asociación con otros grupos tipológicos. Como en los dos casos anteriores, son las manos de molino las que se cuentan por mayor cantidad. Sin embargo, el registro cambia notablemente en lo referente a la proporción que adquieren los morteros. De hecho, si se comparan el total de oquedades correspondientes a morteros con el número de superficies activas de manos de molinos, las primeras son más abundantes.

En lo que respecta al diseño de los artefactos, el mismo se caracteriza por una importante diversidad morfológica y dimensional. No se cuenta con datos acerca de la posible relación entre las variantes de tamaño que se registran en las oquedades de 
morteros y usos particulares de los mismos. Sin embargo, es posible que las primeras se deban a una combinación de desgaste diferencial y requerimientos particulares vinculados con distintos montos de sustancias procesadas.

En el caso de los grupos tipológicos restantes, la circunstancia de la diversidad morfológica podría ser mejor comprendida, por un lado, como un resultado de la apariencia de las formas base utilizadas en la manufactura y, por otro, con el punto de la vida útil de los artefactos en los que tuvo lugar su descarte. Esto último se encuadraría en lo que Aschero (1988: 227) denomina tipos morfológicos básicos y transformados, los cuales se encuentran ligados entre sí por relaciones de transformación (mantenimiento y uso). En general, estos no registran una especialización funcional por clases morfológicas determinadas, comportándose más bien como instrumentos multipropósito. La excepción estaría constituida por las piezas destinadas únicamente al procesamiento de recursos no comestibles, las cuales se caracterizan por tamaños reducidos, materias primas poco abrasivas, ausencia de manufactura y eventual utilización con otros fines (p.e., percutores). Estos últimos se relacionarían con una estrategia "oportunística” (Nelson 1991).

$\mathrm{Al}$ interior de ciertos grupos es posible discriminar algunas piezas por su grado de estandarización en cuanto a forma y tamaño. En el caso de los morteros, la selección de materias primas, y las proporciones entre ancho máximo/profundidad de oquedades pequeñas y grandes se encuentran estandarizadas. Por su parte, las manos de molino presentan tendencias en lo referente al área de la superficie activa y tipo de manipulación -con dos brazos-, aunque las materias primas utilizadas en la manufactura son variadas. El grado de fragmentación que caracteriza a los molinos impide efectuar mayores consideraciones en este sentido, en tanto que las manos de mortero no reúnen esas características.

La selección de materias primas líticas para la manufactura de los artefactos mantiene, en gran medida, las características correspondientes al momento anterior. Sin embargo, se registran dos variantes de importancia, aunque estas se encuentran numéricamente poco representadas. Se trata de artefactos manufacturados sobre basandesitas y granitos cataclásticos disponibles a más de $20 \mathrm{~km}$ de distancia de las localidades de uso (Babot 2004). Ambos casos corresponderían a una búsqueda de atributos petrográficos destinados a mejorar en parte la eficiencia y/o intensidad de uso, principalmente, mediante una mejor abrasión y menor contribución de elementos de la roca en las sustancias molidas, en circunstancias de un uso frecuente e intenso del instrumental de molienda. Esto, aun a expensas de mayores requerimientos de tiempo destinado al proceso de manufactura, mantenimiento y limpieza del mismo.

El conjunto artefactual correspondiente al lapso analizado presenta una importante inversión en su manufactura, además de que la misma alcanza a más del 80\% de los artefactos y, con frecuencia, es de tipo polimodal. Las técnicas de formatización se encuentran afectando tanto a las superficies activas de molienda, así como a las zonas de prensión. Como novedad se registran piezas con un importante trabajo de regularización que se aprecia en una parte considerable de su superficie total, incluyendo zonas neutras y de apoyo de artefactos pasivos. Además, tiene lugar con frecuencia el rebajado de entornos de oquedades de morteros. Este conjunto de modificaciones implementadas sobre las formas base originales está destinado a potenciar los atributos naturales de las materias primas de abrasión, confort para la prensión y retención del producto molido. Todas ellas apuntan a mejorar la eficiencia de uso de los artefactos y contribuir a la intensidad de molienda.

Varias de las estrategias técnicas mencionadas han sido descritas en algunos de los artefactos más tempranos. Los nuevos elementos de diseño implementados están representados por los rebajados de entorno de oquedades de morteros y por la configuración subtriangular asimétrica mediante lascado más picado, o bien, solamente picado de zonas de prensión en ciertas manos de molino. Los mismos están dirigidos, por un lado, a contener cantidades importantes de recursos de moler y evitar pérdidas de producto molido $y$, por otro lado, a facilitar un asimiento prolongado de los artefactos activos.

Asimismo, se registra una recurrencia en la utilización de técnicas para el mantenimiento de las superficies activas y la administración del desgaste en artefactos de los cuatro grupos tipológicos que presentan un importante desgaste por uso (Adams 1999). Esto último se dirige a prolongar la vida útil de formas base apropiadas más que de superficies activas, y está representado por una diversidad de procedimientos que implican la rotación de las piezas. Este 
conjunto de decisiones técnicas se vincularía con la preservación de instrumentos confortables y/o ya manufacturados en situaciones de molienda intensa y frecuente (Adams 1993). Este comportamiento sería el responsable de una parte importante de los artefactos fracturados, cuya ruptura habría ocurrido durante el repicado de zonas activas.

Anteriormente se mencionó que las manos de molino se caracterizan por presentar tendencias en cuanto a tamaños de superficies de molienda. En efecto, más de la mitad de estas superan los $200 \mathrm{~cm}^{2}$, duplicando, triplicando o cuadruplicando el área de molienda registrada en momentos precedentes y con ello, el monto de producto molido en la misma proporción. Este aspecto constituye una de las decisiones tecnológicas más importantes puestas en marcha con el objetivo de una mayor eficiencia de molienda. El empleo de dos brazos requeridos en la manipulación de dichos artefactos, a la vez que favorece una mayor inversión de fuerza durante el procesamiento, contribuye a aliviar la fatiga muscular en situaciones de molienda intensa (Adams 1993, 1999).

Los artefactos móviles y fijos se comportan como equipamiento permanente del sitio con el fin de un uso recurrente en el marco de estrategias de movilidad residencial reducida (Olivera 1992). La selección de formas base fijas para la manufactura de morteros implica, además, la delimitación espacial de la práctica mediante la construcción de "espacios de molienda". Esto constituye una estrategia de preparación para un uso prolongado o recurrente. En el mismo sentido podría ser interpretada la posibilidad de una organización grupal de la tarea en torno de los artefactos múltiples fijos (Adams 1996). Al respecto, es notoria la recurrencia en la selección de grandes bloques con buena disponibilidad de superficies subplanas naturales con este fin.

Los recursos de molienda mantienen los repertorios taxonómicos diversos que caracterizan al momento anterior (Babot 2004). Estos debieron poseer un papel muy importante en la dieta de los grupos agropastoriles en su carácter de "recursos de reaseguro" y en el marco de situaciones de riesgo de producción (p.e., eventualidad del fracaso en la producción; Escola 1996). Es en este momento que la molienda aparece también vinculada a otras actividades diferentes de la subsistencia. Tienen lugar nuevos usos de los artefactos, que pasan a integrar las secuencias de manufactura y elaboración de bienes y materiales no consumibles (p.e., producción cerámica, preparación de pigmentos minerales, materiales de construcción, entre otros; Babot 2004).

Las circunstancias que rodean a la molienda entre los grupos productores de Antofagasta de la Sierra indican que la misma constituye una práctica planificada, desde la selección de las materias primas, el diseño y manufactura de los artefactos, la implementación de técnicas para prolongar su vida útil y la organización espacial de las actividades. Las características de los artefactos señalan que hubo una búsqueda deliberada de eficiencia y que tuvo lugar una importante intensidad de molienda. Cualquiera de las siguientes opciones parece adecuarse a la situación registrada desde ca. 2000 años AP en adelante (sensu Adams 1993, 1996): a) menos tiempo invertido en el procesamiento $y$ mayor disponibilidad horaria para participar de otras actividades (en situaciones de riesgo de trabajo o de mano de obra; Escola 1996); b) mayor cantidad de producto molido o un número mayor de gente alimentándose del mismo.

\section{Conclusiones}

En este trabajo se efectuó una caracterización de la molienda en Antofagasta de la Sierra, Puna Meridional argentina, desde sus primeras manifestaciones en el área hacia $c a .6500$ años AP hasta el momento agropastoril más tardío. Se analizó el proceso de cambio de la mencionada tecnología, desde sus primeras manifestaciones en contextos de grupos cazadores recolectores del Holoceno Medio, pasando por las sociedades agropastoriles hasta $c a$. 1100 años AP y las que se sitúan en la transición. La magnitud de las modificaciones ocurridas durante la transición hacia la producción, un punto central de la investigación, pudo ser mejor comprendida en su comparación con los elementos asignados a momentos previos y posteriores, a lo largo del citado intervalo temporal.

Para el análisis del cambio tecnológico en el largo plazo se emplearon los conceptos de eficiencia e intensidad de uso de los artefactos. Estos permitieron establecer tres momentos en la organización de la práctica de la molienda en Antofagasta de la Sierra, que marcan situaciones de intensificación creciente de la misma entre $c a$. 6500-1100 años AP. Las circunstancias de cambio a lo largo de la secuencia ocupacional del área son, a nuestro juicio, las de una reducción de la movilidad/cambios en 
las pautas de asentamiento, sumadas a situaciones de riesgo de subsistencia y de trabajo/mano de obra (Escola 1996), en el marco de modificaciones en la organización socioeconómica de los grupos prehispánicos. En este contexto, la importancia de la molienda estaría estrechamente asociada con el aprovechamiento de una gama amplia de recursos de almacenamiento (Babot 2004).
Agradecimientos A Carlos Aschero y Salomón Hocsman con quienes discutí varios aspectos de este trabajo. A Lizzie Pintar, Marisa López Campeny, Lorena Cohen, Carlos Aschero y Salomón Hocsman por facilitarme parte de los artefactos que se analizaron.

\section{REFERENCIAS CITADAS}

ADAMS, J. L., 1993. Toward understanding the technological development of manos and metates. Kiva 58 (3): 331-334.

-1996. Manual for a technological approach to ground stone analysis. Center for Desert Archaeology, Tucson.

-1999. Refocusing the role of food-grinding tools as correlates for subsistence strategies in the U.S. Southwest. American Antiquity 64 (3): 475-498.

ALBECK, M. E., 1993. Contribución al estudio de los sistemas agrícolas prehispánicos de Casabindo (Puna de Jujuy). Tesis doctoral, Facultad de Ciencias Naturales, Universidad Nacional de La Plata, La Plata.

ASCHERO, C., 1988. De punta a punta: Producción, mantenimiento y diseño en puntas de proyectil precerámicas de la puna argentina. Precirculados del IX Congreso Nacional de Arqueología Argentina, Simposio Las unidades de análisis para el estudio del cambio cultural en arqueología, pp. 219-229. Buenos Aires.

1999. El arte rupestre del desierto puneño y el Noroeste Argentino. En Arte rupestre en los Andes de Capricornio, J. Berenguer y F. Gallardo (Eds.), pp. 97-135. Museo Chileno de Arte Precolombino, Santiago.

-2000a. Figuras humanas, camélidos y espacios en la interacción circumpuneña. En Arte en las rocas. Arte rupestre, menhires y piedras de colores en Argentina, M. Podestá y M. de Hoyos (Eds.), pp. 15-44. Sociedad Argentina de Antropología, Buenos Aires.

2000b. El poblamiento del territorio. En Nueva Historia Argentina, vol. 1 Los Pueblos originarios y la conquista, M. Tarragó (Ed.), pp. 17-59. Editorial Sudamericana, Buenos Aires.

ASCHERO, C. y J. G. MARTINEZ, 2001. Técnicas de caza en Antofagasta de la Sierra, Puna Meridional argentina. Relaciones de la Sociedad Argentina de Antropología 26: $215-241$.

ASCHERO, C., D. ELKIN y E. PINTAR, 1991. Aprovechamiento de recursos faunísticos y producción lítica en el Precerámico Tardío. Un caso de estudio: Quebrada Seca-3 (Puna Meridional argentina). Actas del XI Congreso de Arqueología de Chile T II, pp. 101-114. Santiago.
BABOT, M. P., 2004. Tecnología y utilización de artefactos de molienda en el noroeste prehispánico. Tesis de Doctorado en Arqueología, Facultad de Ciencias Naturales e Instituto Miguel Lillo, Universidad Nacional de Tucumán, San Miguel de Tucumán.

2005. Plant resource processing by Argentinian Puna hunter-gatherers (ca. 7000-3200 BP): Microffosil record. The Phytolitharien, Bulletin of the Society for Phytolith Research 17 (2): 9-10.

BABOT, M. P., C. A. ASCHERO, S. HOCSMAN, M. C. HAROS, L. G. GONZALEZ BARONI y S. URQUIZA, 2006 Ms. Ocupaciones agropastoriles en los sectores intermedios de Antofagasta de la Sierra (Catamarca): Un análisis desde Punta de la Peña 9.I.

BAMFORTH, D. y P. BLEED, 1997. Technology, flaked stone technology, and risk. En Rediscovering Darwin: Evolutionary theory and archeological explanation, M. Barton y G. Clark (Eds.), pp. 109-139. Archeological Papers of the American Anthropological Association 7.

COHEN, M. L., 2005 Ms. Entre guano y arena... ocupaciones recurrentes: un caso de estudio en el sitio Punta de la Peña 9-III Antofagasta de la Sierra, Catamarca. Trabajo final de la Carrera de Arqueología, Facultad de Ciencias Naturales e Instituto Miguel Lillo, Universidad Nacional de Tucumán, San Miguel de Tucumán.

DIEHL, M., 1996. The intensity of maize processing and production in upland Mogollon pithouse villages AD 200-1000. American Antiquity 61 (1): 102-115.

ESCOLA, P., 1996. Riesgo e incertidumbre en economías agropastoriles: Consideraciones teórico-metodológicas. Arqueología 6: 9-24.

2000. Tecnología lítica y sociedades agropastoriles tempranas. Tesis para optar al grado de Doctor en Filosofía y Letras, Universidad de Buenos Aires, Buenos Aires.

FRANCO, N. V. y L. BORRERO, 1996. El stress temporal y los artefactos líticos. La cuenca superior del río Santa Cruz. En Arqueología. Sólo Patagonia. Ponencias de las Segundas Jornadas de Arqueología de la Patagonia, J. Gómez Otero (Ed.), pp. 341-348, Centro Nacional Patagónico, CONICET, Puerto Madryn. 
GARCIA, L. C., 1998. Arqueología de asentamientos formativos en la Puna Oriental y su borde, Provincia de Jujuy: El cambio hacia una vida crecientemente sedentaria y productiva en Azul Pampa, Departamento de Humahuaca. Tesis Doctoral, Facultad de Filosofía y Letras, Universidad de Buenos Aires, Buenos Aires.

GARCIA, S. P., D. ROLANDI y D. OLIVERA, 2000. Puna e historia. Antofagasta de la Sierra, Catamarca. Asociación Amigos del Instituto Nacional de Antropología, Buenos Aires.

HARD, R. J., R. P. MAULDIN y G. R. RAYMOND, 1996. Mano size, stable carbon isotope ratios, and macrobotanical remains as multiple lines of evidence of maize dependence in the American Southwest. Journal of Archaeological Method and Theory 3 (4): 253-317.

HOCSMAN, S., 2002. ¿Cazadores recolectores complejos en la Puna Meridional argentina? Entrelazando evidencias del registro arqueológico de la microrregión de Antofagasta de la Sierra (Catamarca). Relaciones de la Sociedad Argentina de Antropología 27: 193-214.

2006. Producción lítica, variabilidad y cambio en Antofagasta de la Sierra, ca. 5500-1500 AP. Tesis para optar al Grado de Doctor en Ciencias Naturales, Facultad de Ciencias Naturales y Museo, Universidad Nacional de La Plata, La Plata.

HOCSMAN, S., M. P. BABOT, S. MAMANI, C. HAROS, A. CALISAYA, A. JERONIMO, L. GONZALEZ BARONI y E. MILENA, 2003. La transición de cazadores recolectores a sociedades agropastoriles en Antofagasta de la Sierra (Catamarca) vista desde el sitio Peñas Chicas-1.3. Resúmenes de las VI Jornadas de Comunicaciones de la Facultad de Ciencias Naturales e Instituto Miguel Lillo, p. 17. San Miguel de Tucumán.

HOCSMAN, S., J. G. MARTINEZ y C. ASCHERO, 2004 Ms. Obtención de recursos distantes en la porción meridional de los Andes Centro Sur: Una visión desde la puna argentina. En Before farming. En prensa.

HORSFALL, G. A., 1987. Design theory and grinding stones. En Lithic studies among the contemporary Highland Maya, B. Hayden (Ed.), pp. 332-337. University of Arizona Press, Tucson.

LANATA, J. L., 1996. La diversidad instrumental en el norte de Península Mitre, Tierra del Fuego. Arqueología 6: 159-197.

LANATA, J. L. y L. BORRERO, 1994. Riesgo y arqueología. En Arqueología de cazadores recolectores. Límites, casos y aperturas, J. L. Lanata y L. Borrero (Eds.), pp. 129-144. Arqueología Contemporánea 5, Edición Especial, Buenos Aires.

LOPEZ CAMPENY, S. M., 2001 Ms. Actividades domésticas y organización del espacio intrasitio. El sitio Punta de la Peña-9 (Antofagasta de la Sierra, Prov. de Catamarca). Trabajo final de la Carrera de Arqueología, Facultad de Ciencias Naturales e Instituto Miguel Lillo, Universidad Nacional de Tucumán, San Miguel de Tucumán.
LOPEZ CAMPENY, S. M., D. E. OLIVERA, V. FERNANDEZ VARELA y J. PEÑA, 2005. Procesos tafonómicos, subsistencia y uso del espacio: Análisis de la arqueofauna de un sitio agropastoril de la Puna Meridional argentina (Punta de la Peña 9, Antofagasta de la Sierra, Catamarca). Intersecciones en Antropología 6: 11-28.

MORRISON, K. D., 1994. The intensification of production: Archaeological approaches. Journal of Archaeological Method and Theory 1 (2): 111-149.

1995. Fields of victory. Vijayanagara and the course of intensification. Contributions of The University of California, Archaeological Research facilities, Berkeley.

NELSON, M., 1991. The study of technological organization. En Archaeological method and theory, vol. 3, M. Schiffer(Ed.), pp. 57-100. The University of Arizona Press, Tucson.

NELSON, M. y H. LIPPMEIER, 1993. Grinding-tool design as conditioned by land-use pattern. American Antiquity 58 (2): 286-305.

NUÑEZ, L., M. GROSJEAN e I. CARTAJENA, 1999. Un ecorrefugio oportunístico en la Puna de Atacama durante eventos áridos del Holoceno Medio. Estudios Atacameños 17: 125-174.

OLIVERA, D., 1992. Tecnología y estrategias de adaptación en el Formativo (Agroalfarero Temprano) de la Puna Meridional argentina. Un caso de estudio: Antofagasta de la Sierra (Provincia de Catamarca, Argentina). Tesis para optar al grado de Doctor en Ciencias Naturales, Facultad de Ciencias Naturales, Universidad Nacional de La Plata, La Plata.

2001. Sociedades agropastoriles tempranas: El Formativo Inferior del Noroeste Argentino. En Historia argentina prehispánica, E. Berberián y A. Nielsen (Eds.), T. I, pp. 83-125. Editorial Brujas, Córdoba.

OLIVERA, D. y J. R. PALMA, 1997. Cronología y registro arqueológico en el Formativo Temprano en la Región de Humahuaca. Avances en Arqueología 3: 77-99.

OLIVERA, D., P. TCHILINGUIRIAN y M. J. DE AGUIRRE, 2002 Ms. Cultural and environmental evolution in the meridional sector of the Puna of Atacama during the Holocene. En XIV International Congress of Prehistoric and Protohistoric Sciences. B.A.R. International Press, Bélgica. En prensa.

OLIVERA, D. y S. VIGLIANI, 2000-02. Proceso cultural, uso del espacio y producción agrícola en la Puna Meridional argentina. Cuadernos del Instituto Nacional de Antropología y Pensamiento Latinoamericano 19: 459-481.

PEREZ GOLLAN, J. A., 1991. La cultura de La Aguada vista desde el valle de Ambato. Publicaciones 46: 157-173.

PINTAR, E. S., 1996. Prehistoric Holocene adaptations to the Salt Puna of Northwest Argentina. Ph. D. Dissertation, Southern Methodist University, Dallas. 
2004 Ms-a. Cueva Salamanca 1: Ocupaciones humanas en la Puna Sur en el lapso 7600 a 6200 A.P. En Actas del XV Congreso Nacional de Arqueología Argentina, Facultad de Humanidades y Ciencias Sociales, Universidad Nacional de Río Cuarto, Río Cuarto. En prensa.

2004 Ms-b. Cueva Salamanca 1: Ocupaciones altitermales en la Puna Sur. Relaciones de la Sociedad Argentina de Antropología. En prensa.

PODESTA, M., 1986-87. Arte rupestre en asentamientos de cazadores recolectores y agroalfareros en la Puna Sur argentina. Antofagasta de la Sierra, Catamarca. Relaciones de la Sociedad Argentina de Antropología 17 (1): 241-263.

RODRIGUEZ, M. F., 1998. Arqueobotánica de Quebrada Seca-3: Recursos vegetales utilizados por cazadores recolectores durante el Período Arcaico en la Puna Meridional argentina. Tesis Doctoral, Facultad de Ciencias Exactas y Naturales, Universidad de Buenos Aires, Buenos Aires.
— 1999. Explotación de recursos vegetales durante el Arcaico en la Puna Meridional argentina. Presentación de un caso: Quebrada Seca-3. Actas del XII Congreso Nacional de Arqueología Argentina, T III, pp. 345-351. La Plata.

SCATTOLIN, M. C., 1990. Dos asentamientos formativos al pie del Aconquija: El sitio Loma Alta (Catamarca, Argentina). Gaceta Arqueológica Andina 5 (17): 85-100.

WRIGHT, K., 1994. Ground-stone tools and huntergatherer subsistence in Southwest Asia: Implications for the transition to farming. American Antiquity 59 (2): 238-263.

YACOBACCIO, H., 1997. Sociedad y ambiente en el N.O.A. precolombino. En De hombres y tierras. Una historia ambiental del Noroeste Argentino, C. Reboratti (Ed.), pp. 26-38. Proyecto Desarrollo Agroforestal en Comunidades Rurales del Noroeste Argentino, Salta. 